\title{
ARGUEDAS Y RULFO: \\ DOS NARRATIVAS QUE SE ENCUENTRAN
}

POR

JORGE RUFFINELLI

Universidad Veracruzana, México

E1 «Primer diario» de José María Arguedas, fechado en Santiago de Chile el 10 de mayo de 1968, con el que abre su última e inconclusa novela El zorro de arriba y el zorro de abajo (1971) ${ }^{1}$, es no sólo el testimonio de una preparación suicida para la muerte, sino también un ajuste de cuentas con la literatura latinoamericana, a la que pertenecía el autor. Las referencias a varios escritores del continente y el señalamiento de sus simpatías y diferencias al respecto establecen las coordenadas en que Arguedas se ubica al saberse incluido en el grupo de sus contemporáneos.

Esas coordenadas son dobles: por una parte, lo separan y alejan precisamente de ese grupo, en la medida en que su experiencia literaria y humana es bastante singular. Conocemos algunos rasgos de su situación: criado en un medio indígena no siéndolo él, aprendiendo el quechua antes o al mismo tiempo que el español, escribiendo literatura en un idioma que no era el idioma "afectivo», Arguedas se sintió siempre más cerca y comprometido con el mundo quechua que con la civilización española y mestiza. Pero, por otra parte, y puesto que escribió novelas y cuentos, y éstas y éstos fueron acogidos en el espacio de lo que se designa como literatura peruana y, más ampliamente, como literatura latinoamericana, su pertenencia cultural se vio ampliada (o amplificada), aun cuando no hubiese sido en absoluto de su voluntad, y su nombre y obras pasaron al venero común de estas literaturas.

De ahí que en el «Primer diario» se proponga separar las aguas y establecer quiénes están de un lado y quiénes de otro. No lo hace en

\footnotetext{
1 José María Arguedas, El zorro de arriba y el zorro de abajo (Buenos Aires: Losada, 1971).
} 
un nivel ensayístico o teórico, al contrario, por ejemplo, de un Vargas Llosa, con su «Novela primitiva y novela de creación en América Latina», que también constituye, desde su propia perspectiva, otro aparte de aguas. Arguedas expresa sus extrañamientos de algunos escritores y las cercanías a otros, intentando racionalizar y justificar objetivamente sus afirmaciones.

Señalo este hecho sin entrar en su análisis, porque me interesa extraer del conjunto de autores nombrados por Arguedas (João Guimarães Rosa, Julio Cortázar, Carlos Fuentes, Juan Carlos Onetti, Alejo Carpentier, Nicanor Parra, Gabriel García Márquez, José Lezama Lima, Mario Vargas Llosa, Juan Rulfo, etc.) a uno hacia quien la aproximación parece haber sido mayor: Juan Rulfo. A Rulfo le dedica Arguedas algunas de las frases más entrañables y emotivas del "Primer diario», y su reconocimiento como hombre y escritor es total, sin cortapisas. La elección de Rulfo (la que hace Arguedas y la que hacemos nosotros ahora para subrayarla) no resulta arbitraria. Sus mundos literarios se corresponden más allá de las diferencias, y parecería haber en ambos un modo de acercamiento a sus personajes y a sus historias, tal vez similares. $O$ de una entonación semejante, aunque fuese en el pathos, en la densidad trágica con que se ve y se expresa el desarrollo de la vida a través del arte. Por eso, y porque en los términos con que se refiere a Rulfo parece traslucirse el deseo de una consideración propia, parecida, es interesante hacer una lectura de esas páginas, así como de un artículo poco conocido, que en el año 1960 Arguedas dedicó a «reflexionar» sobre Rulfo ${ }^{2}$.

Estos dos textos, distanciados ocho años entre sí, tienen una curiosa diferencia, otra que la de su oportunidad y contexto. El artículo de 1960 señala una y otra vez las excelencias literarias de Rulfo, pero ante todo las diferencias entre su mundo y el «nuestro», esto es, el peruano, desde el punto de vista de un escritor que está en ese momento escribiendo para sus connacionales. En cambio, el texto de 1968 marca la proximidad, no las diferencias; marca la familiaridad que los une dentro del más amplio sector de la literatura latinoamericana. En ese texto, el «Primer diario», el lector en perspectiva es otro que el de 1960: ya no se trata del lector peruano, sino del latinoamericano, y dentro de este último, en particular, de sus propios pares, los escritores que emergieron rotundamente a la consideración crítica y a la lectura en los años sesenta.

${ }^{2}$ José María Arguedas, «Reflexiones peruanas sobre un narrador mexicano», Suplemento dominical de El Comercio (Lima, 8 de mayo de 1960). Reproducido en Texto crítico, año IV, núm. 11 (septiembre-diciembre 1978), pp. 213-217. 
Con fecha 11 de mayo de 1968, el «Primer diario» dice: «Ayer escribí cuatro páginas. Lo hago por terapéutica, pero sin dejar de pensar en que podrán ser leídas.» Curiosamente, el discurso monologante del «Diario» adopta de repente, en varios momentos, la forma vocativa y se dirige a un tú, como en el ejemplo de Rulfo. Después de señalar que desde 1944 ha leído «muy poco» y añadir: «Me acuerdo de Melville, de Carpentier, de Brecht, de Onetti, de Rulfo», se vuelve súbitamente al último: «¿Quién ha cargado a la palabra como tú, Juan, de todo el peso de padeceres, de conciencias, de todo el peso de placeres, de conciencias, de santa lujuria, de hombría, de todo lo que en la criatura humana hay de ceniza, de piedra, de agua, de pudridez violenta por parir y cantar, como tú? » $\mathrm{Y}$ después de esta caracterización de la palabra-«cosa», de la palabra material, pasa a recordar los encuentros de ambos en Guadalajara o en Berlín, y la actitud de igualdad indeclinable en el trato que le dispensara Rulfo, actitud esta última que Arguedas valora sobremanera y que le recuerda a un personaje del mundo quechua. «Me acordé de la primera vez que te conocí en Berlín, de cómo te llevé del brazo al ómnibus, con cuánta felicidad, como cuando, ya profesional, volví a encontrar a don Felipe Maywa, en San Juan de Lucanas, y ide repente! me sentí igual a ese gran indio al que había mirado en la infancia como a un sabio, como a una montaña condescendiente. ¡Igual a él! Y mientras los otros poblanos me doctoreaban, estropeándome hasta la luz del pueblo, él, don Felipe, me permitió que lo tomara del brazo. Y sentí su olor de indio, ese hálito amado de la bayeta sucia de sudor.» La cita es extensa, y podría serlo aún más, porque Arguedas, como en un torrencial regreso al pasado mediante la memoria, abunda en los recuerdos de don Felipe, para volver otra vez a enlazar ese recuerdo con el de Rulfo: «Por eso me trató de igual a igual, como tú, Juan, en Berlín, y en Guadalajara, y en Lima, también en ese pueblo de Guanajuato, fregado hasta nomás, como el Cuzco.» El mayor homenaje a Rulfo consiste, de partida, en establecer este paralelo que lo asocia con el cerrado mundo de la infancia arguediana.

Al par de las circunstancias biográficas y de la simpatía mayor o menor hacia sus contemporáneos latinoamericanos, es de destacar, en el primer fragmento recordado, una concepción poética: para Arguedas, la palabra literaria más valiosa es aquella que lo recoge todo de su mundo circundante para expresarlo en su cabal densidad y riqueza. La idea ya estaba en el «Diario» un poco antes, cuando el 10 de mayo atribuye a su encuentro con una mujer («zamba gorda, joven, prostituta»), la recuperación del roto vínculo con las cosas. «Cuando ese vínculo se hacía intenso —añade Arguedas- podía transmitir a la palabra la 
materia de las cosas.» De modo, pues, que esta relación con el mundo, ya se trate de un tipo sensorial, místico o literario, tiene la virtud distintiva de dotar al lenguaje de una particular densidad expresiva: la palabra misma absorbe la materialidad del mundo. Y lo que distingue a los escritores auténticos, raigales, de los que no lo son, afirma implícitamente Arguedas, es esta cualidad.

Otras referencias a Rulfo tienen que ver con un concepto escurridizo, el del "profesionalismo» del escritor, que Arguedas toma en su costado más vulnerable, hasta hacer por momentos una sátira con él, pero que le sirve asimismo para establecer otra demarcación literaria. Así, contra las opiniones de Cortázar en torno a este concepto, Arguedas arremete con estilo iterativo: "Yo no soy escritor profesional; Juan [Rulfo] no es escritor profesional; ese García Márquez no es escritor profesional. ¡No es profesión escribir novelas y poesías! O yo, con mi experiencia nacional, que en ciertos resquicios sigue siendo provincial, entiendo provincialmente el sentido de esta palabra oficio como una técnica que se ha aprendido y se ejerce específicamente, orondamente para ganar plata.» Arguedas es claro al señalar su limitado concepto del profesionalismo literario, que no resuelve una polémica en la que, diríamos, tienen razón todos los contendientes, dado que no emplean el término en el mismo sentido. Lo que importa aquí no es dar o restar razón a la afirmación de Arguedas, sino comprenderlo como una defensa de la escritura literaria que no atiende - ya que no le preocupa- su carácter económico, y que con esa prescindencia gana en autenticidad.

Los dos criterios señalados - la materialidad de la palabra literaria, el carácter artesanal (no-profesional) de la literatura- son los que emplea Arguedas para distinguir y valorar a los escritores latinoamericanos. $\mathrm{Y}$ en ambos casos, Rulfo tiene una mención privilegiada: por su carácter ejemplar y por su cercanía a la propia concepción literaria de Arguedas. En estas menciones (así como en las negativas que atañen a otros escritores) es cierto que Arguedas reacciona emocionalmente, pero aun cuando no explaye sus bases teóricas, también es cierto que utiliza criterios que responden a un modo de la producción literaria y al resultado artístico de una escritura que tiene por objeto final no a la palabra misma, sino al hombre y a la comunidad en que aparece esa palabra. En dichas coordenadas, Arguedas sitúa lo mejor de la literatura contemporánea, a Rulfo (y a Guimarães Rosa) en particular, y extensivamente a sí mismo, al menos como expresión de deseos y como intuición del camino que ansiaba recorrer y que, en efecto, decimos nosotros, había recorrido hasta los Zorros.

A diferencia del «Primer diario», el artículo de 1960 se dirige a 
un lector nacional, como indiqué antes, a quien Arguedas considera provechoso introducir los rasgos de estilo y de mundo de Rulfo, implicadas sus diferencias con la cultura nacional. No hay en este texto exaltación emotiva, sino un análisis de la situación literaria puesta en contraste con la literatura peruana. No en vano Arguedas tituló su artículo «Reflexiones peruanas sobre un narrador mexicano".

Un rápido desglose de lo que a Arguedas más le ha llamado la atención en la literatura de Rulfo, así como de los conceptos literarios generados en el proceso, permitiría distinguir las siguientes fases de su artículo:

a) Arguedas comienza señalando la imbricación entre individuo y nación, así como la función que tiene la literatura en la formación de los valores nacionales. «El hombre hace la literatura y después la literatura contribuye a modelar al hombre. Las artes forman la médula de un país, rigen al ser humano...» Esa literatura, a su vez, no surge de un individualismo autárquico, sino de la experiencia histórica. De ahí que, en respuesta a un profesor inglés que le señalara haber encontrado en Ciro Alegría, "por primera vez, luego de arduas lecturas de la narrativa latinoamericana, un hálito de ternura», Arguedas le dijese: «El continente es así. Luchamos en condiciones igualmente despiadadas y terribles; nuestra obra es fruto de nuestra vida». Pero en este punto Arguedas reconoce que el campesino peruano es diferente del mexicano en que «no está embriagado por la sed de la sangre ni aun de la venganza», rasgos que encontrará muy hondamente enraizados en México.

b) Si ésta es la diferencia fundamental entre el mundo campesino de Rulfo y el peruano, Arguedas la explica en los términos culturalistas y míticos de los extranjeros que llegaron a México en los años treinta y cuarenta (como Lawrence y Lowry), es decir, percibiendo una atmósfera ominosa y fulgurante a la vez. "El país ejerce sobre las personas sensibles una fascinación en que la angustia es quizá tan granđe como el deslumbramiento.» $\mathrm{Y}$ ello, dice Arguedas, por la presencia constante de la muerte, porque la «facilidad con que se espera y se provoca la muerte en todas partes está siempre presente. Se huele a la muerte; su presencia constante parece casi necesaria para comprender y conocer la esencia de las maravillas que en ese país se contemplan». Cae aquí Arguedas en el estereotipo de la «muerte mexicana», que tanto los extranjeros aludidos como la propia Revolución mexicana de 1910, la reflexión filosófica sobre el «ser mexicano» y los escritores modernos, como Paz y Fuentes, ayudaron a crear. Pero lo singular de sus observaciones es que permiten advertir cómo lo fascinaba el tema de la muerte. Incluso 
confiesa: «Por eso leí febrilmente los cuentos de El llano en llamas y la novela Pedro Páramo, de Juan Rulfo.»

c) En tercer lugar, Arguedas destaca el «arte» narrativo de Rulfo, recalcando sus rasgos distintivos, por ejemplo: «Los bosques de México, los campos calcinados y esa jubilosa, casi estentórea y natural forma en que el hombre mexicano celebra la lucha y la muerte; la raíz que nadie podría descubrir de este modo de ser, no está explicada por Rulfo, pero ninguno como él nos lleva a su más íntima morada.» Una literatura, pues, que expresa sin explicar y que en esa actitud llega a lo más profundo y sutil de la experiencia. Para Arguedas esto se consigue al elevar a categoría de arte el "difícil lenguaje del pueblo». De ahí que destaque el hecho singular de que "muchos de los relatos de El llano en llamas y gran parte de Pedro Páramo están escritos en primera persona y es siempre un campesino quien habla. Esta hazaña de Rulfo es quizá la mayor», añade Arguedas, valorando el «genio» con que ha creado ese lenguaje narrativo.

d) La literatura capta en sus personajes más logrados, como la Susana San Juan de Pedro Páramo, «todas las raras esencias del pueblo», pues no en vano su función es interpretar a esa colectividad. Por eso, señala Arguedas, «creo que nada del ingente mundo mexicano ha dejado de ser interpretado en estos dos breves libros». Más aún: Arguedas le atribuye a Rulfo la aptitud, la sensibilidad literaria y social de haber captado esa nueva clase y ese nuevo grupo étnico, el mestizo, que «hoy emerge como una clase impetuosa, impulsada por valores aún no bien definidos», y que «en México entró en ebullición más pronto, durante la Revolución nacional, pero aún sigue siendo una inmensa clase angustiada que da manotazos. La revolución aparentemente no le dio una verdadera salida o la frustró». De todos modos, añade Arguedas, «los relatos de Rulfo nos lo muestran mejor que ninguna otra pintura que hayamos visto». De ahí la diferencia que señala también sobre la composición étnica de sus mundos: en Rulfo, el protagonista social es el mestizo; en el mundo de Arguedas es el indio. En Pedro Páramo «no se descubre, como es fácil hacerlo en el Perú andino, la presencia muchas veces plural del señor colonial en los dueños de los pueblos. Esas gentes han cambiado mucho, se han transformado y convertido en un producto nuevo, en unos modos nuevos y un lenguaje propio, que Rulfo maneja con una sabiduría artística que constituye uno de los milagros mayores de su obra».

e) Y finalmente -aunque es detalle mucho menor-, Arguedas diluye en apenas una posible «resonancia de Faulkner en algunas de sus imágenes», el peso de las influencias o «modelos» ajenos a la cultura 
1atinoamericana. Al contrario, confía en que esta literatura podrá proponer su modelo e influir «sobre los países europeos en los que ha empezado a difundirse y de los que hasta hace poco siempre estuvimos copiando». Y la razón es que «en Rulfo se levanta un poderoso mundo».

Como puede verse, el artículo de 1960 es generoso en el reconocimiento de la calidad de los textos de Rulfo. Pero como señalé antes, varias veces insiste Arguedas en sus diferencias con la literatura peruana. Este procedimiento comparatista le sirve para perfilar mejor los rasgos de la narrativa de Rulfo sobre el trasfondo de la cultura peruana, pero de paso también le sirve para fustigar las pequeñas miserias de esa cultura, como cuando señala el «desprecio por el habla popular».

Es constante el señalamiento de esas diferencias. He aquí algunos ejemplos:

Hay pocas semejanzas entre el hombre que describe Rulfo en sus relatos y el campesino de nuestro país. Siempre se ha hablado de estas semejanzas y se las ha considerado como evidentes. Lo evidente son las diferencias.

... Nada del ingente mundo mexicano de los pueblos ha dejado de ser interpretado en estos dos breves libros... Y la muerte especialmente, así como los otros elementos que sostienen la vida: el placer en todas sus formas; la embriaguez sexual y la de la música; la embriaguez religiosa; pero, sobre todo, las infinitas formas de la miseria, de la tortura humana sobre la tierra, están presentes en estos libros. $Y$ todas esas formas no son iguales a las nuestras.

En estos relatos que comentamos el indio aparece una sola vez y como un individuo absolutamente marginal. Casi no figura. [En cambio], entre nosotros es la materia envolvente, ocupa el primer plano.

En México no se siente desprecio por el habla popular como en el Perú. En nuestro país se ha tomado el castellano «mal hablado» casi únicamente para hacer reír a los mentecatos a costa de la gente del pueblo.

El caballo [de Miguel Páramo] se fatiga de muerte porque ha matado a su dueño. No habría ocurrido cosa semejante en el Perú campesino. Acaso al caballo le hubieran brotado ríos de lágrimas o música de los ojos, alguna música solemne y taladrante; pero no esta inquietud que no hay otra forma de calmar que la muerte.

Estas diferencias no disminuyen la importancia del mundo y la literatura de Rulfo, como tampoco de la literatura y el mundo peruanos, sino 
que se establecen como coordenadas de situación. $Y$, sin embargo, Arguedas señala que aun con esas diferencias, la narrativa de Rulfo es mucho más próxima que la de los "grandes novelistas europeos y norteamericanos». De ahí que asevere: «Todos debiéramos leer los relatos de Juan Rulfo, especialmente los peruanos, precisamente porque revelan un mundo distinto al nuestro, muy distinto, pero como hecho de una materia semejante.» Esa materia la proporcionan «lo que tienen de español y de antiguo americano»: por eso, aunque haya sufrimiento en esta literatura, no se trata del "gemiqueo» existencialista ni de las formas atormentadas del «fatigado hombre europeo». El valor de estas páginas de Arguedas estriba, entre otras cosas, en que reconocen un modo de ser latinoamericano en contraposición con el europeo o el anglosajón de los Estados Unidos. De ahí la cercanía más allá de las distancias, la familiaridad por encima de las separaciones.

\section{FINAL}

Podría establecerse un cotejo de las observaciones de Arguedas sobre la literatura de Rulfo y las que el mismo escritor mexicano ha expresado en diferentes entrevistas a propósito de la literatura en general o de su propia obra. Hay algunas coincidencias de relieve, que nos permiten reconocer en parte una concepción semejante del ejercicio literario, de la función de la literatura, de su dimensión histórica, del concepto de palabra.

Así, por ejemplo, al señalamiento de Arguedas de que «Rulfo emplea términos del castellano viejo conservados por el campesino y fundidos con palabras que ha deformado a su modo...», encontramos un correlato en las afirmaciones de Rulfo sobre el uso del lenguaje en Pedro Páramo: "Hay palabras que el diccionario llamaría arcaísmos: es que aún esos pueblos hablan del lenguaje del siglo xvI. Ahora, no se trata de un retrato de ese lenguaje; está traspuesto, inventado, más bien habría que decir: recuperado» ${ }^{3}$. En cuanto a la observación sobre el contingente social y étnico que la narrativa de Rulfo recoge, el mismo escritor mexicano lo ha dicho: «El mexicano es una mezcla de español y el indígena. Un español quizá de Extremadura, por ahí de Castilla, que al alearse tomó costumbres españolas pero bajo un sincretismo que incluía el paganismo, su superstición, su forma de pensar e imaginar las cosas.» De

${ }^{3}$ Ernesto González Bermejo: «Juan Rulfo: la literatura es una mentira que dice la verdad», Revista de la Universidad de México, vol. XXXIV, núm. 1 (septiembre de 1979), pp. 4-7. 
este mismo mestizaje, según Rulfo, surge la actitud mexicana ante la muerte: «El mexicano propiamente de clase baja y hasta de cierta clase media baja es, por regla general, fanático religioso, y entonces el culto a los muertos es algo común en él. Tenemos un cuarenta por ciento de población con esas características» (González Bermejo, p. 5). Y en cuanto al concepto de palabra literaria, Rulfo es más concreto y escueto que Arguedas, pero interesa señalar la importancia que le concede a la historia y el desinterés, por no decir desprecio, que siente por la literatura, cuyo objeto último es la palabra. "¿Qué es para usted la palabra?», le pregunta Ernesto González Bermejo. Y Rulfo contesta: «Un instrumento para construir un lenguaje y contar una historia. La novela, su nombre lo dice: 'Señores, yo les traigo a contar esto.' Ahora [en cambio] muchos escriben la palabra por la palabra misma; la moda es escribir por escribir, importa poco la historia, sólo la forma» (p. 7).

Sobre José María Arguedas, Rulfo se ha referido varias veces con respeto y admiración, aunque sin el tono de exaltación del «Primer diario». Haciendo una revisión de la literatura latinoamericana, ubica a Arguedas en la «misma corriente» que Asturias, esto es, en una literatura que recobra el caudal mítico del pueblo de «la América indígena». Allí está, dice Rulfo, «una gran obra, Yawar fiesta (1940), Los ríos profundos (1957), etc. Arguedas también trata la mitología indígena mostrándola mezclada con las costumbres de la realidad actual del Perú» ${ }^{4}$.

Sin duda aún podría continuarse este rastreo y enriquecerlo con otros textos de Rulfo. Yo he querido dar un conjunto de ejemplos, mayormente desde la perspectiva de Arguedas, con el propósito de mostrar cómo estas dos narrativas dialogan y se encuentran desde la conciencia de sus autores. Y ello porque el punto de intersección, por encima de las obvias disimilitudes, está en una común vivencia del hecho literario. Vivencia que se racionaliza en sus opiniones sobre literatura y que llega a reconocerse en la lectura mutua.

${ }^{4}$ Sergio Franca Danese, «Reflexiones sobre la literatura hispanoamericana (y brasileña» (Entrevista con Juan Rulfo), Movimiento (São Paulo). Reproducido en Sábado, suplemento de Unomásuno, núm. 98 (29 septiembre 1979), pp. 2-3. 
